\title{
Sub-Regional Cooperation in Central Europe - Past, Present and Future
}

\author{
GEBHArD, Carmen ${ }^{1}$
}

\begin{abstract}
There is a plethora of sub-regional arrangements that involve Central European countries. This article takes the Visegrád Group as an example of a minor range sub-regional grouping of states that can influence politics at a larger scale, and how this specific impact has changed in recent years following the transformation of the circumstances conditioning Central Europe's geostrategic position.
\end{abstract}

\section{Introduction}

Sub-regional cooperation in Central Europe has a long-standing tradition. There is a plethora of sub-regional arrangements that involve Central European countries, such as the Central European Free Trade Agreement (CEFTA), the Central European Initiative (CEI), the South East Europe Cooperation Initiative (SECI) as well as trilateral formations, e.g. between romania, Hungary and Austria, or Romania, Poland and Ukraine. However, the most significant manifestation of Central european cooperation at the sub-regional level is the so-called Visegrád Group (VG), which came into being and is named after a summit held by four Central European countries in Visegrád/Hungary in February 1991. Preceding the creation of the VG, as consisting of the Czech republic, Hungary, Poland, and Slovakia, there had been Austrian ambitions to form a Central European bloc of cooperation ("Projekt Mitteleuropa" - project Central Europe) based on the historical common ground of the Austro-Hungarian Empire. ${ }^{2}$ It was only the formation of the VG, however, that had a more lasting and also political impact on the post-Soviet development of the Central European core region. ${ }^{3}$ This article therefore takes the VG as the most significant case of sub-regional cooperation to show how this sort of minor range sub-regional grouping of states can influence politics on a larger scale, and how this specific impact has changed in recent years following the transformation of the circumstances conditioning Central Europe's geostrategic position. This article places particular emphasis on the security-political relevance of the VG as such, and of the changes it has undergone since its inception.

1 Email: carmengebhard@hotmail.com

2 This Austrian initiative towards the creation of a cooperative arrangement for "Mitteleuropa" led i.a. to the creation of the so-called "Pentagonale" in 1989 (including Austria, Italy, Hungary, yugoslavia and Czechoslovakia, and after the inclusion of Poland in 1991, the "Hexagonale". These formations had a strong focus on science, culture and education, and largely refrained from taking on more sensitive political agendas. It was first divided about budgetary issues, and that kept them from any greater impact, and ultimately, the collapse of yugoslavia and the escalation of tension between Serbia and Croatia constituted a major drawback for the cooperative framework. In 1992/93, the Hexagonale was turned into the Central European Initiative (CEI) to include Bosnia, Croatia and Slovenia. Today, the importance of CeI lies mainly in the area of scientific and cultural exchanges.

3 One of the main reasons why neither the Pentagonale nor the Hexagonale held potential for a long-lasting and distinct impact on the development of the Central European core region is that the constellation of countries involved was too heterogenic in terms of historical legacy, future strategic objectives, and regional interests. The inclusion of yugoslavia and its subsequent breakdown in the course of the Balkan wars certainly played a decisive role. In any case, the inclusion of both Italy and Austria also produced some internal competition for moral and political leadership within the formation. See MAIEr (1993) p. 8. 
The accession of the four VG states to the European union (Eu), and their joining of NATO respectively are regarded as crucial turning points in this overall development. ${ }^{4}$

\section{Rationale, Analytical Framework and Methodology}

This article adopts a qualitative view on the development of sub-regional formations in Central Europe while the central focus lies on the transformation of objectives of the VG as one of the most significant cooperative arrangements in this region. The article sets out an analytical framework based on international scholarship on regional and sub-regional coordination.

The methods employed include process-tracing, qualitative literature review and content analysis. The material used mainly consists of secondary literature and key policy documents. Other primary sources such as treaties and conventions have been consulted in terms of indirect information gathering and as such they are not cited explicitly in the text.

\section{Conceptualizing Sub-Regional Cooperation in the Context of Security}

Sub-regional cooperation and sub-regionalism respectively can be defined as being constituted by an intensified or structured relationship between geographically adjacent entities to facilitate both inter-state and sub-state level cooperation in certain selected issue areas. As for the area of security and defence, sub-regional cooperative formations are often perceived marginal, as in most cases they mainly address "soft" security issues, and as such hardly ever gain centre stage in high politics. However, these sub-regional arrangements, which were in the past often discarded as secondary or tertiary players - or as Bailes ${ }^{5}$ put it, as the "cinderellas of European security" - in recent years, have been more and more acknowledged as highly influential elements in the multi-level setting of European security actors. With the transformation of security conceptions towards a broader comprehensive and inclusive understanding of the notion, the value of these groupings has started to get more attention and rightful recognisance.

The pragmatic issues that these groupings are usually focussed on, such as investment promotion, trade liberalization, private sector support, transportation, telecommunications, environmental protection, natural resources management, cultural and educational exchanges, tourism, border crossing facilitation, and energy management are increasingly seen from the point of view of confidence-building and are thus more acknowledged to have security enhancing effects. ${ }^{6}$ According to a comprehensive security approach as it has recently been adopted by all major security organizations including NATO, the $\mathbf{u N}$, the Eu, and the OSCE, these sub-regional frameworks are indeed well-suited to encounter new types of threats and security challenges like terrorism, organised crime, drugs and arms proliferation, human trafficking, natural and man made accidents, illegal migration or minority issues. The principle this effect is based upon is conflict avoidance through enhancing integration in multiple issue areas, which as such reflects much of the classical integration theory of neo-functionalism that suggests "spill-over" as the basic effect driving integration. As the following section will argue, however, more generally, classic integration theories offer fairly little analytical substance for the analysis and explanation of sub-regionalism as a manifestation of inter-state and sub-state cooperation.

4 The Czech republic, Hungary and Poland joined NATO in 1999, Slovakia followed in 2004, and they all together joined the Eu on 1 May 2004.

5 BAILES (1997) p. 28.

6 POP (2001) p. 133. 


\section{Theorizing Sub-Regional Cooperation}

As pointed out above, the classic theory of integration through cooperation as suggested by neo-functionalism offers limited explanatory value for the analysis of sub-regional cooperation. The same could be said about intergovernmentalist accounts of integration or European integration more specifically. The specific line of argumentation based on an explicit focus on states as primary actors reduces the applicability of different variants of Intergovernmentalism to cases below the meta-level of European integration.

In the case of European integration theory, generally, two different patterns of theory application can be distinguished: ${ }^{7}$

- firstly, sub-regional cooperation can be treated as a micro-cosmic version of european integration, putting sub-regional and regional (i.e. European) integration at the same level of analysis, and thus suggesting a direct application of the respective bulk of theory to a specific minor-range case such as the VG.

- secondly, European integration theory could be employed as a framework, i.e. for the analysis of the inter-level relationship and ratio between the regional (i.e. European) and the sub-regional integration process in a specific region, e.g. Central europe.

As the explanatory value of European integration theories has been considered as fairly limited in this second regard, ${ }^{8}$ specialist literature on this issue has rather adopted a systemic and more clinical view on sub-regionalism, trying to grasp in the first place, how sub-regional arrangements relate functionally to forms of cooperation or integration at larger scales, such as the so-called "regional" scale in the case of the Eu. Such an analytical perspective is closer to the realm of International relations theory than integration theory proper. What it borrows from the integration theoretical perspective, however, is the basic idea that regional and sub-regional formations could not only constitute subordinate and as such complementary levels of cooperation following similar logics of interaction but that they could also be seen as two substantially different things. Integration on the regional meta-level and the sub-regional meso-level could even be seen as two diametrically opposed processes which each in their own way take nation states beyond the state level of interaction. This is to say that in the course of integration at the European level power and governance is dislocated "upwards" to the supranational level while in the case of sub-regional forms of integration this movement goes "downwards" to regional (and local) entities." This aspect is also reflected by Downs: ${ }^{10}$

"At the dawn of the twenty-first century, twin forces continue to stretch the nation-state in opposite directions. States as they enter the new millennium are transformed not only by the centripetal pull of supranational integration, but also by the centrifugal forces of resurgent Regionalism. [...] Uncertainty generated by these countervailing forces prompts powerful and contentious arguments about the normative and empirical roles of subnational actors in increasingly complex webs of multi-level governance."

Even though, depending on the perspective, these two dynamics do not always occur in terms of "countervailing forces" it should be taken into account that the alleged permanent cleavage between supranational "integratedness" and regionalist affixedness is likely to affect a nation state's foreign policy orientation. (Sub-) Regionalism may also influence a state's membership conduct

7 GEBHArD (2008) p. 74.

8 See e.g. PArKEr (2000)

9 AMIN (2002) p. 387.

10 DOWNS (2002) p. 174. 
and thereby have a positive or negative effect on the process of macro-level integration. These potentially conflicting dynamics between a macro-level entity and meso-level formations that intersect with the catchment area of the former are widely neglected in most theoretical models on regional (and European) integration.

research on the phenomenon of sub-regionalism, which has also been studied under the label of "New regionalism", ${ }^{11}$ has also dealt with the relationship between two other apparently diverging dynamics that emerged in the Post Cold War World: (Sub) regionalism and Globalization. Movements and tendencies towards (sub)regionalization and globalization have been observed concurrently. Some experts have explained the increase of sub-regional activities as a direct effect or reaction of states to globalization. ${ }^{12}$ Scholars have stated that many of these sub-regional formations have taken on important balancing and stabilizing functions to counter the multiple effects globalization can have, most particularly for small states. ${ }^{13}$ The particular asset of sub-regional forms of cooperation indeed lies in their potential to reflect specific concerns that are shared between a group of geographically adjacent states - concerns, which in broader contexts of integration such as the European or the transatlantic could be neglected in the long run. ${ }^{14}$ This implies that the long term success of sub-regional forms of cooperation and integration highly depends on the constellation of states working together and the internal balance among them. Drulák ${ }^{15}$ underlines in his assessments about the Benelux that internal structural homogeneity, common history as well as shared political objectives and long-term aims build essential criteria for sustainable success in sub-regional contexts. Besides their similarity, states cooperating in a sub-regional framework also profit from instances of economic or cultural interdependence.

\section{Towards a Typology of Sub-Regionalism}

It is generally one of the main conceptual questions that arises from the notion of $s u b$-regionalism: how does the minor scale or sub-regional formation relate to the bigger whole, e.g. for the case of Central Europe, to the wider framework of European integration, which is regional in reach and comprises many issues that might also be dealt with at the sub-regional level by either state or sub state actors through varying intensities of cooperation. Dangerfield ${ }^{16}$ distinguishes between four alternative types or modes of subregional cooperation. According to his assessment, sub-regional formations can be classified as

- pioneering,

- substituting cooperation or integration at higher levels,

- complementary in this respect.

Pioneering cooperation at the sub-regional level involves higher degrees of integratedness on a certain issue area, which in a second instance exerts influence on meta-level integration. One of the most typical examples in this regard is the Benelux Group which essentially pioneered in different economic areas and most particularly in customs and border management matters. There are good reasons to see the Benelux Group as an influential and inspiring precursor of the european Communities.

11 TELò (2001)

12 E.g. SCHIrM (2002)

13 rüLAND (2002) p. 201.

14 KISS-KöNIGOVA-LuIF (2003)

15 DruLÁK (2000)

16 DANGErFIELD (2004) p. 246. 
Substituting formations occur when states form cooperation on the sub-regional level as an alternative to a larger scale integration project, which could either be more or less committal than the minor scale formation in the making. Such an alternative constellation has certainly been built by the European Free Trade Association (EFTA), which was even explicitly intended to build a less far-reaching alternative to membership in the European Communities. In the case of EFTA, substitution did not take place in terms of conflictive sidelining of the main "european project". It is important to point out, however, that this sort of substituting formation could also be employed in order to counter another formation. In this case, however, the relationship is rather that of two conflicting regional cooperation projects than of a sub-regional formation seeking to replace a respective meta option. Dangerfield ${ }^{17}$ also mentions the subtype of formations that are "substituting involuntarily", pointing out that in some instances states might be forced to build up alternative formations because accession to a dominant formation is out of reach. This could be seen as being the case with the so-called "european Neighbourhood" which has been defined by the eU as comprising all states bordering the union without a mid or long term perspective of membership. What Dangerfield ${ }^{18}$ defines as complementary sub-regional cooperation in practice mainly appears in the context of pre-accession scenarios, meaning that sub-regional formation follows the aim of proactively preparing a group of states for the accession to a meta scale formation, e.g. the European union for the Central European candidates before accession in 2004. One of the typical examples here for the economic field is the creation of CeFTA.

As will be argued further below, the VG has fitted neatly into the type of complementary sub-regional formation, promoting approximation and accession to the Eu as a major political aim from its very outset. Elements of cooperation aiming at substituting the broader framework of European (and Transatlantic) integration are not existent in the VG context. The VG as such could even be said to have fulfilled the function of a pre-accession instrument, preparing the four countries for full membership in both NATO and the Eu, based on a joint effort and conviction.

In contrast to movements of sub-regional integration in other parts of Europe, ${ }^{19}$ the Central European aspirations in the context of the VG have never assumed the character of a sidelining minor range alternative to the overall regional integration processes. In the course of the pre-accession processes with Central and Eastern Europe, both the Eu and NATO directly related the candidate countries' ability and ambition to resolve conflicts with neighbouring states conditionally with their prospects for membership..$^{20}$ Initiatives for sub-regional cooperation were thus welcomed as complementary to the overall aim of broader regional integration. Central and East Europeans were encouraged to conclude treaties affirming existing borders and guaranteeing ethnic minority rights and to establish new forms of cooperation, i.a. cross-border economic zones and joint peacekeeping forces. ${ }^{21}$

Given this close link of the VG with the joining of the meta level process of European and transatlantic integration turns the question of its post-accession role into an important one. What

17 DANGErFIELD (2004) p. 247.

18 DANGErFIELD (2004) p. 247.

19 Previous research that I (see Gebhard 2008) have conducted in the area of sub-regional cooperation in the Baltic Sea region has shown that some cooperative arrangements put in place by either sub-regional actors or states in the region were aimed at sidelining the wider European integration process, and any regional policies that might have been launched and driven by the European core in Brussels. This has been the case with the so-called Northern Dimension (ND) of the European union and the Swedish attitude in the context of the creation of the Council of the Baltic Sea States (CBSS). Instead of sticking with the broader objective of performing like a fully fledged eU member state - like Finland did in the context of the ND - Sweden, on many different occasions, clearly favoured the sub-regional forum offered by the CBSS, and placed it as a priority above the objective of European integration.

20 BAILES-COTTEy (2006) p. 199.

21 KAVALIAuSKAS (2003) 
in fact is cooperation in the context of the VG, after the four countries have reached their common goal of firstly joining NATO and secondly eU accession? What political aims now build the framework for the cooperation between these states? And what in particular has changed in respect to the security political relevance of the VG? In search of viable answers to these questions, this article will first turn to a historical overview of sub-regional cooperation in Central europe up to the year of 2004, i.e. the political turning point, when the V4 finally joined the eU, and were therefore not only part of the transatlantic community but also of the more narrow circle of Eu member states.

\section{Sub-Regional Cooperation in Central Europe in the post Cold War Era}

After the breakdown of the bipolar world order and the end of the Cold War, a number of sub-regional formations emerged in Central Europe. Despite their functional and political differences, most of these formations were created in the framework of the broader aim of "returning to Europe" or "reintegrating to the West". These sub-regional arrangements took on various different functional frameworks, ranging from mutual trade liberalisation to more generic cooperation e.g. in order to enhance leverage vis-à-vis the Eu, ${ }^{22}$ and coordination around pre-accession issues. It can be said that generally, these various sub-regional groupings which emerged in Central Europe after the seminal year of 1989 have played important roles in respect to the reconstructing of the international security order, albeit on a very low profile. In a way they helped to fill the political vacuum $^{23}$ that resulted from the breakdown of the Warsaw Pact and the dissolution of the CMEA (Council for Mutual Economic Assistance), and reconnected states that were just about to explore the opportunities and responsibilities emerging from the new geostrategic setting. ${ }^{24}$ Much of this wave of sub-regional formation that caught many parts of Europe after the end of the Cold War was constituted by the re-emergence of long-dormant regional patterns of cooperation that had until then be dominated by the superpower overlay. ${ }^{25}$

The Central European Initiative (CeI) was the first sub-regional formation created after the end of the Cold War. It was founded in 1989 under label of "Pentagonale" as a political, economical, cultural and scientific organisation which aimed at supporting its members in approaching the goal of Western integration. Austria, Italy, (then) Czechoslovakia, Hungary, Poland, and (then) yugoslavia were among the founding members although Poland joined only one year later to form the "Hexagonale"; in 1992 CEI was joined by Slovenia, Bosnia and Herzegovina, Croatia, and the Fy republic of Macedonia, in 1995, Albania, Belarus, Bulgaria, Moldova, and romania, in 2000, Serbia, in 2006, Montenegro. Taking in the yugoslavian states eventually turned out to weaken the initiative as such. The more states joined the CEI, the more heterogeneous it became, and the less leverage it generally had in respect to meso and meta range levels. The CEI generally kept a rather low profile, connecting its member states in uncontroversial matters such as culture and education in the first place. ${ }^{26}$

Economic cooperation and integration in Central Europe took place in the framework of the Central European Free Trade Agreement (CEFTA), which was concluded in 1992. In a way, CEFTA could be regarded as a close relative of the VG. However, from its very outset, CEFTA had exclusively limited its activities to the realm of economic cooperation and trade liberalisation respectively.

22 DANGErFIELD (2008a) p. 137.

23 DWAN (2000) p. 89.

24 BAILES (1997) p. 28.

25 HyDE-PrICE (1997) p. 14.

26 DANGErFIELD (2008) p. 644. 
CEFTA has thus always had a more clear-cut functional agenda than the VG. All participating countries signed association agreements with the Eu, and more generally, the CEFTA was a forum for accession preparation. In contrast to the VG, CEFTA therefore also changes its membership constellation depending on whether a state has already joined the Eu or not. After joining the Eu in 2004, the V4 left CEFTA as a direct result of the full membership. In terms of its functional constitution, VG has therefore always been more closely related to the CEI than to the CEFTA. What connects the latter two though is the shifting geographical scope of their activities: with the Central European states approaching Eu accession both CEFTA and CEI were reoriented towards taking in the Southeastern countries on the Balkans, and added considerable heterogeneity to their internal constellation.

As pointed out in the introduction, by contrast, the VG fulfilled a special role in various respects: Its membership structure remained stable throughout the years, its constellation therefore ultimately homogenous, and its political agenda fairly consistent. The following abstract seeks to outline the constituting years of the VG, and thereby, to assess on which political aims the cooperative formation was build upon. This should help to allow further analysis about how its agenda has changed throughout the years, and most particularly after the V4 have joined the European union.

\section{The Visegrád Group - its inception and early years}

The VG was formally inaugurated at a meeting of Czechoslovakia, Hungary, and Poland, the so-called V4 (with today the Czech republic and Slovakia), which was held in Bratislava in April 1990 following an initiative by Václav Havel on mutual policy coordination and the synchronization of future steps towards regional integration. Due to the fact that at this point particularly the Hungarian and the Polish delegations were still dominated by communists of the Soviet era, progress in the multilateral talks were fairly modest. Only by the end of 1990 and in early 1991 did the process of sub-regional formation gain new momentum. At a meeting of the then three founding members in February 1991 in Budapest, the so-called Visegrád Declaration was signed. The dominating argument in the declaration built on the common past and shared historical experiences that would compel the states to cooperate at a larger scale. The presidents, foreign ministers and selected parlamentarians of the three states recognized the potential this sort of sub-regional cooperation could bear for their long term stance in European matters of integration. $^{27}$

The specific setting in the years 1990 and 1991 truly gave the three post communist states "no alternative to cooperation". ${ }^{28}$ On the one hand, they sought to disentangle from the CMEA, Warsaw Pact and Soviet legacy, on the other hand, there had been broad awareness that joining the West was a yet far away option, and that in this particular setting, even the most reformist post communist regimes could be expected to be openly welcomed by the West. ${ }^{29}$ In its first years of existence, the VG did not show persistent levels of activity and proactivity respectively. Accordingly, throughout the years, there have been phases where the VG as a sub-regional formation was less visible and thus less influential than in other times. Analysts have detected one such low profile phase in the years between 1993 and 1998, when compared to the very first years of 1990-1992, the VG seemed to lose most of its momentum. It appears important to point out that shortly after its inception, the VG adopted a fairly ambitious political agenda explicitly including so-called hard power issues such as the dismantling of old Soviet structures and overcoming the totalitarian

27 COTTEy (1999) p. 74.

28 VACHuDOVA (1993) p. 39.

29 DANGErFIELD (2008) p. 645. 
past by way of security and defence cooperation and common concerted transformation. There is empirical evidence that in August 1991, during the coup in Moscow, there were political and military consultations among the V4. ${ }^{30}$ This sort of sensitive involvement has not been repeated at any other point of the VG's existence; however, the VG states established a system of coordination in security and defence issues, agreed on measures for closer cooperation in military technology development, production and procurements, and they concluded each a bilateral military cooperation agreement with the others. ${ }^{31}$

From the very beginning, the V4 also sought to get closer to the political project of European integration, which at this point did not yet have any explicit security or defence related element. When in December 1991 the Eu decided to sign Europe Agreements with the V4, their proactive stance shown in the form of sub-regional jointness had been one of the major criteria for the Eu to grant them this sort of privileged status. There is evidence that the Krakow Treaty, that was signed in December 1992 to create CEFTA, would not have come into being if the Central European states had not yet shown their ambition towards regional integration in the form of the VG.

The way VG cooperation touched upon issues of security after 1992 was rather through indirect stabilizing effects than through explicit security or even defence related integration. An important aspect in this regard was that the VG states managed to sort out ideological divergences among themselves, which also had an impact on their shared conviction about which framework would best suit each their strategic necessities. In the early years of the VG, there had been internal divisions about whether the Central European states should be geared to a pan-European security framework as then constituted by the Organization for Security and Cooperation in Europe (OSCE) or rather a more comprehensive transatlantic framework as offered by NATO. The V4 used the group as a forum to discuss the advantages of each setting, and to negotiate about whether association or membership in NATO was at all desirable and feasible. These instances of convergence were highly conducive to the fact that the then three states increasingly had to be dealt with by third partners as a single entity. Being addressed as a group of integrated states by the Eu constituted a major advantage for the post communist states as unavoidably, it helped them to pool their qualities and balance each others political and economic shortfalls to enhance their leverage as a group. "Visegrád" as a label became highly visible in the early years of the group's existence, and it was increasingly seen as Central europe's defining entity, that external actors had to address if they wanted to interact with any one of the participating states. ${ }^{32}$ One of the decisive factors supporting this effect was surely the group's comprehensive functional agenda, which covered political issues as much as matters of research, culture and education. This also helped the V3 to be addressed more directly from outside..$^{33}$

It appears important to point out that at this early stage of the VG, cooperation was mostly a high level elite issue with fairly little involvement of subregional actors and actors of the civil societies. According to some analysts ${ }^{34}$ this was mainly due to the lingering influence of the Soviet and communist legacy, which prevented the political leaders from moving their interactions with lower levels beyond the sphere of discussion and planning. The very strong focus on the overarching aim of "returning to the West" also put the emphasis of acting power with the governing level of the three states.

30 ruSNAK (2001) p. 249.

31 COTTEY (1999) p. 75.

32 FAWN (2001) p. 54.

33 COTTEY (1999) p. 76. 


\section{The intermediate phase 1993-1998}

Scholars who have sought to trace the development of VG internal dynamics identified the period of 1993 to 1998 as a period of passivity and decline. ${ }^{35}$ One of the conditioning factors was that after the division of Czechoslovakia, both the Slovakian and the Czech leadership turned against the VG as a framework for subregional cooperation. The years of 1992 and 1993 also saw the emergence of tensions between Hungary and Slovakia, which for themselves hampered cooperation in the VG framework. To many observers of the time it looked like the VG was going to decline before at all reaching its most fundamental aims. To some extent, even the establishment of CEFTA held the potential to undermine the leverage and purpose of the $\mathrm{VG}$, as it took away much of the attention and appeared to offer a reliable framework for itself. This period also saw the rapid deterioration of Slovakia in its process of approaching the transatlantic security system and European integration process. Instead of adopting and cultivating a cooperative air, the V4 immersed in divergences and fell back into isolasionist and individualist thinking. ${ }^{36}$

In 1994, at the NATO summit in Prague where the V4 were to meet uS president Bill Clinton to discuss their future relationship with NATO, the Czech defence minister declined to join his fellows from the other VG states stating that he was not convinced of any lobbying strategies to precede these sorts of negotiations. ${ }^{37}$ The subsequent exclusion of Slovakia from NATO and Eu membership negotiations constituted another drawback in the very short history of the VG and fuelled the general criticism both regional and international analysts had raised beforehand. Some critics declared the VG as "clinically dead", others instead ascertained that the group was going through a "dormant phase of transformation", which however, would be succeeded by more active times. ${ }^{38}$ During this period, CEFTA in turn experienced a phase of high visibility and activity, which exacerbated external impression about the alleged crisis of the VG. CEFTA also took on much of the Eu pre-accession agenda, which had lost momentum in the VG framework. It is important to point out, however, that until CEFTA expanded in 1996, the CEFTA summits provided important opportunities for keeping up the dialogue among the V4. Cooperating within the framework of CEFTA helped to rebuild confidence in sub-regional formations, and as such, it certainly helped to pave the way towards a reactivation of the VG in the form of "Visegrád 2". ${ }^{39}$ Another decisive factor that brought the V4 leaders to cooperate more closely was the progress in approaching NATO, which became most evident in 1997 when the formal membership invitation was issued to Poland, Hungary and the Czech republic. The deteriorating position of Slovakia in this regard did not impede further efforts in reviving the $\mathrm{VG}$ as a forum for sub-regional cooperation. ${ }^{40}$

\section{Reactivation and Visegrád 2 until the 2004 EU Enlargements}

The reactivation of the VG in 1998 was to a very large extent only possible after both in the Czech republic and in Slovakia the political leadership had changed towards a more pro-VG team. These high level changes also marked the end of the strong superiority complex, which had previously kept the Czech republic from fully investing in a cooperative framework. Individualistic and

\footnotetext{
35 DANGErFIELD (2008) p. 652.

36 VACHuDOVA (1993) p. 40.

37 COTTEY (1999) p. 77.

38 DANGErFIELD (2008) p. 657.

39 DANGErFIELD (2002) p. 98.

40 rHODES (1999) p. 54.
} 
competitive tendencies abated to leave room for a more cooperative air. This phase also saw the first steps towards the rehabilitation of Slovakia in respect to the eU and - to some extent - also to NATO, although clearly it was still lagging behind its V4 partners. Although the progress of Poland, Hungary, and the Czech republic towards NATO accession made the inequalities and Slovakian shortfalls more obvious, the general movement had a positive impact on the dynamics inside the VG. The motive of "assisting Slovakia" in catching up gained momentum and fuelled cooperation in the framework of the VG. Most of all the Czech republic had a clear interest in keeping Slovakia up to the pace of integration as a disjunction of the accession processes to the Eu would have caused a series of practical problems, e.g. in respect to their bilateral customs agreement that had been concluded upon the division of Czechoslovakia. ${ }^{41}$

The CEFTA summit held in Prague in September 1998 served as a forum for the V4 to prepare the reactivation of the VG. The reconvened VG then met in October 1998 in Budapest to define a new agenda for "Visegrád 2". This new agenda was characterized on the one hand by a stronger recourse to the original aims of integration to the West, i.e. the accession to both NATO and the Eu, and on the other hand by a clear focus on intra- $\mathrm{VG}$ cooperation activities i.a. in the areas of foreign affairs, internal affairs, education, culture, society, science, technology, environment, infrastructure, and cross-border cooperation. Cooperation in foreign affairs was meant to include mutual consultation and information transfer as well as strategic concentration of actions in the context of NATO and Eu pre-accession processes. Internal affairs cooperation was to include issues such as border and immigration affairs, fight against organised crime as well as fight against human and drug trafficking. ${ }^{42}$ What was also new to the VG framework was the establishment of early forms of institutionalization of the intergovernmental cooperation. The constitutive leaders felt a need to formalize their relationships within the group in order to on the one hand secure stability and continuity, and on the other hand to support the growing functional agenda and its implementation. From then on, the V4 met at least twice a year (a) in president formation, (b) foreign minister formation, and - as needed (c) the formation of other ministers. regular meetings were also foreseen for the ambassadors of the V4 and the parliamentary representatives. As another structural innovation, the V4 established the institution of a rotating presidency, which as an instrument had already been employed successfully by other sub-regional formations in other parts of Europe. ${ }^{43}$

Another decisive novelty has been the establishment of the so-called International Visegrád Fund (IVF), which essentially marked the transition of the VG's activities towards a more formalized type of sub-regional organization. The main idea behind the creation of the fund was to enable the formation to adopt a more hands-on approach in the region and to allow the V4 to complement their external activities with measures and initiatives concerning its internal sphere. The plan was to provide funding in the realm of education, arts, culture, science and technology in the first place - which in fact were all low profile issues. However, given this new asset of having its own financial instrument, the sense of activity also changed towards a more proactive and dynamic attitude, which undoubtedly added new momentum to the VG as a whole. It appears important to point out that the IVF was established as a truly permanent institution with its own staff and dedicated premises. The IVF also established a system of obligatory financial commitment among the V4, and as such, considerably strengthened the internal morale and level of allegiance and loyalty. ${ }^{44} \mathrm{The}$

41 DANGErFIELD (2008) p. 644.

42 For more detailed information on the "Visegrád 2" agenda, consult the 1998 annual report available online at www. visegradgroup.org.

43 GEBHArD (2008) p. 85.

44 DANGErFIELD (2008) p. 645. 
existence of such a binding and formalizing framework also enhanced the visibility of the VG in the region as such and fostered working relations with various civil society actors. Some observers also pointed at the normative effect such a formal institution could have by giving "meaning to the rather abstract idea of a regional identity". ${ }^{45}$

This formative phase in the development of the VG also saw the introduction and establishment of the "V4 plus" in the overall internal and - even more importantly - external rhetorics with cooperation partners at various levels. Coining the four states as belonging to one distinct group and formation already had considerable impact on the visibility and the way they were seen and addressed from outside - be it by other states or the Eu or NATO. Adding the "plus" now was to communicate the openness of the formation to cooperation with third parties at all levels, which again enhanced the overall leverage and visibility of the VG beyond its own regional sphere. Some critics ${ }^{46}$ also pointed out that the "V4 plus" formula had to be seen as the result of a weak compromise between the four about whether the formation should be opened to enlargement. until today, the V4 have not been able to agree on any such extension of their regional reach, which may either be a reason why the group managed to persist, or a reason why it has reached and passed its functional zenith already.

\section{The Post-Accession Role of the VG}

From late 2002 onwards, when one of the major goals of the VG appeared within secure reach Eu accession of the V4 including rehabilitated Slovakia - discussions started about the potential post-accession role the formation could take in pursuing the interests common to the Central European region. This was indeed a crucial moment in time that - according to some observers - decided about the dissolution or continuation of the group. What was particularly decisive is the fact that much of the purpose of the VG to exist at all was bound to its activities in pre-accession matters. It was therefore legitimate to raise the question whether the VG was actually still needed once the Eu accession had been performed. The end of 2002 marked the beginning of - as it first looked like - a fairly low profile phase of reflection, during which each of the V4, for themselves and in mutual exchange, would seek to figure out a future political agenda that would keep the group alive. What then happened among the V4, and most particularly between Hungary and the Czech republic, in the years preceding their accession to the Eu, however, fuelled speculations about the "clinical death of Visegrád", about 11 years after its inception, and even the "end of Central Europe". ${ }^{47}$ The most sensational instance where the two alleged regional partners clashed was after the Hungarian Prime Minister, then Viktor Orbán, declared the so-called Beneš decrees as incompatible with the Czech membership in the Eu. Orbán's affront against the Czech republic in this sensitive moment of pre-accession severely troubled the internal relations within the VG and led to repeated situations where both the leaders of the Czech republic and of Slovakia refrained from taking part in VG meetings, leaving the game of four to the two remaining, Hungary and Poland.

In face of these troublesome events, critics exceeded each others imagination in drawing dark pictures of the VG's post accession role. One of the strongest arguments at the time was that there would be little left for a common agenda, once the integration to the West in the form of both NATO and Eu membership had been achieved. Critics pointed at the internal differences and the inherent heterogeneity of the group with Poland rather moving into the direction of taking on a proactive

45 VAuGHAN (2000) p. 1.

46 E.g. DANGErFIELD (2008) p. 646.

47 DANGErFIELD (2008) p. 647. 
role within the Eu and the Czech republic, Hungary and Slovakia rather assuming a defensive and inward-looking if not passive role and style. Also the difference in size and factual political power and leverage between Poland and its VG partners was discussed as a potential divisive factor in the post-accession phase. Pehe ${ }^{48}$, political analyst with a special focus on the VG, suggested that the smaller states of the VG, the Czech republic, Hungary, and Slovakia would soon reorient themselves and seek other frameworks for sub-regional cooperation. Poland in turn would - because of its size and respective political leverage - once a full member of the Eu, turn away from its regional allies and seek closer cooperation with large member states such as Germany and France.

All controversies and criticism aside, at their meeting in May 2004, the V4 decided to continue their cooperation in the framework of the VG and reconfirmed their conviction towards sub-regional forms of cooperation in addition to integration into the Eu. The resulting Visegrád Declaration of 2004 indicated the following four main areas for future activity ${ }^{49}$ and cooperation:

- within the VG,

- within the Eu, i.e. on Eu matters where common regional interests are concerned,

- with other partners be it on state or lower levels,

- within NATO and other international organizations.

The declaration also confirmed the cooperation mechanisms already in place concerning the prime ministerial, ministerial, presidential and parliamentary levels as well as the level of cooperation with other actors from civil society.

\section{Outlook and Conclusion}

The Visegrád Declaration of 2004 has set the framework for the VG's activities after the seminal goal of full Eu membership has been achieved. If one sought to draw conclusions from what has been put out as strategic goals in the early years of the VG and the sort and type of ambitions that can be found in today's version of this very same formation, it is impossible not to ascertain that the profile is considerably lower. From having an identity forming and regionally uniting effect on the states involved and their people, the VG has now turned into a somewhat fuzzy and questionably influential formation. There are reasons to doubt about whether the VG has succeeded in building up a Central European bloc within the Eu, if ever that was the agreed aim of all the four. Looking at the developments since the 2004 accession of the V4 there is a clear orientation of e.g. Poland away from its regional allies towards the power game among the big 6 within the European union. Overt security political discussions have become rare within the VG and as a result also the external effect and visibility of the group as a political formation has lost substance. The very low profile issues that VG cooperation has been about recently might arguably have importance in the perspective of a more comprehensive conception of security. It is nevertheless to be noted that each of the four individually no longer (if they have ever) feel bound to the VG legacy when pursuing their strategic goals within the Eu or also within NATO. In a way, and put more diplomatically, the VG has become more open and informal, which in other words could also be called diluted and less substantial. Despite all these critical factors, however, it must not be denied that the regular meetings as established and institutionalized in the VG framework do keep up some sort of togetherness or "we-feeling", which in a second instance sharpens the V4 awareness about their common interests and potential pay-offs of cooperation, most importantly within the Eu framework. How-

48 PEHE (2004)

49 For more detailed information on the 2004 Visegrád declaration, consult the full text available online at www. visegradgroup.org 
ever, so far there is not very strong evidence that the VG leverage has reached as far as to really establish a Central European group within the Eu. Internal political changes within the national leadership have proved to be powerful intervening factors that very often keep the V4 from really maximizing the cooperation payoffs within the group. More research will be necessary to pin down some of these preliminary conclusions and the VG as such will therefore keep its attractiveness as a meaningful case of complementary sub-regionalism.

\section{Bibliography}

AMIN, Ash: Spatialities of Globalisation. In: Environment and Planning, No. 34/2002, pp. 385-399.

BAILES, Alyson J. K. (1997): Sub-regional Organizations: The Cinderellas of European Security. In: NATO review, Vol. 45:2, March 1997, pp. 27-31.

BAILES, Alyson J. K. - COTTEy, Andrew (2006): regional Security Cooperation in the Early $21^{\text {st }}$ Century. In: SIPrI yearbook 2006. Armaments, Disarmament and International Security. SIPrI Stockholm 2006, pp. 195-223.

COTTEy, Andrew (1999): The Visegrád Group. In: id. (ed.): Subregional Cooperation in the New Europe. Macmillan: Basingstoke 1999, pp. 69-89. https://doi.org/10.1007/978-1-349-27194-8

DANGErFIELD, Martin (2002): Sub-regional Cooperation in Central and Eastern Europe. Support or Substitute for the 'Return to europe'? In: rOSS, Cameron (ed.): Perspectives on the Enlargement of the European union. Brill: Leiden, pp. 95-118.

DANGErFIELD, Martin (2004): regional Cooperation in the Western Balkans. Stabilisation Device or Integration Policy. In: Perspectives of European Politics and Society. Vol. 5:2, pp. 243-272.

DANGErFIELD, Martin (2008): The Visegrád Group in the Expanded European union: From Preaccession to Postaccession Cooperation. In: East European Politics and Societies, Vol. 22:3, pp. 630-667.

DANGErFIELD, Martin (2008a): The Impact of European union Membership on Central European Subregional Cooperation. In PETrITSCH, Wolfgang - SOLIOZ, Christophe (eds.): regional Cooperation in South East Europe and Beyond. Challenges and Prospects. Nomos: Baden-Baden, pp. 129-145. https://doi.org/10.5771/9783845210292-127

DOWNS, William M.: regionalism in the European union. Key Concepts and Project Overview. In: Journal of European Integration, No. 3/2002, pp. 171-177.

DruLÁK, Petr (2000): Zkušenost zemí Beneluxu, cited in KISS/KöNIGOVA/LuIF 2003.

DWAN, renata (2000): Subregional, regional and Global Levels. Making the Connections. In HErOLF, Gunilla (ed.): Subregional Cooperation and Integration in Europe. Conference Papers 26/2000. The Swedish Institute of International Affairs: Stockholm 2000, pp. 81-96.

FAWN, Rick (2001): The elusive Defined? Visegrád Cooperation as the Contemporary Contours of Central Europe. In: Geopolitics 6:1, pp. 47-68. https://doi.org/10.1080/14650040108407706

GEBHArD, Carmen (2008): unravelling the Baltic Sea Conundrum. regionalism and European Integration revisited. Nomos: Baden-Baden 2008. https://doi.org/10.5771/9783845212395

HyDE-PrICE, Adrian (1997): Security and Integration in Mitteleuropa. Towards a New research Agenda. Paper presented at the European Communities Studies Association (ECSA), $5^{\text {th }}$ Biennial Conference, Seattle uSA, May/June 1997.

KAVALIAuSKAS, Tomas (2003): Viségrad, Nato and eU. The Difficult Balancing Acts of the New eU Member States. In: Eurozine 1:2003. www.eurozine.com.

KISS, László - KöNIGOVA, Lucie - LuIF, Paul (2003): Die "regionale Partnerschaft”: Subregionale Zusammenarbeit in der Mitte Europas. In: österreichische Zeitschrift für Politikwissenschaft 32:1, pp. 57-75.

MAIEr, Charles S. (1993): Whose Mitteleuropa? Central Europe Between Memory and Obsolescence. In BISCHOF, Günter - PELINKA, Anton (eds.): Austria in the New Europe. Transaction Publishers: New Brunswick, pp. 8-18. 
PArKEr, Noel (2000): Integrated europe and its 'Margins'. Action and Reaction. In: Id./ARMSTRONG, Bill (eds.): Margins in European Integration. Houndmills 2000, pp. 3-27.

PEHE, Jiři (2004): Is the end of Visegrád in the Offing? Available online at www.pehe.cz.

POP, Adrian (2001): Sub-regional Groupings as Security Providers in Central and Southeastern Europe. In: Medzinárodné Otázky/International Issues, Vol. X:1, 2001, pp. 131-141.

rHODES, Matthew (1999): Post Visegrád Cooperation in East-Central Europe. In: East European Quar- terly 23:1, pp. 51-67.

rüLAND, Jürgen (2002): "Dichte” oder “schlanke” Institutionalisierung? Der Neue regionalismus im Zeichen von Globalisierung und Asienkrise. In: Zeitschrift für Internationale Beziehungen 9:2, pp. 175-208.

ruSNAK, urban (2001): One year Experience of the International Visegrád Fund Activities. In: Central European Political Science review 5:2, pp. 244-251.

SCHIrM, Stefan (2002): Globalization and the New regionalism. Global Markets, Domestic Politics and regional Cooperation. Oxford-Malden, MA 2002.

TELó, Mario (2001) (ed.): European union and New regionalism. regional Actors and Global Gover- nance in a Post-Hegemonic Era. In: The International Political Economy of New regionalism Series. Ashgate: Aldershot et al. 2001.

VACHuDOVA, Milada Anna (1993): The Visegrád Four: No Alternative to Cooperation? In: rFE/rL research report 34:2, August 1992, pp. 38-47.

VAuGHAN, David (2000): Central European Cooperation Goes Into a New Gear. In: radio Prague, August 2000, available online at www.radio.cz. 